\title{
The role of perceptual attitudes of managers in the cognition of employees of the organization
}

\author{
Alla Belousova ${ }^{1}$, Galina Kozhukhar ${ }^{2}$, Maria Vyshkvyrkina $^{3}$, Vladislav Ermak $^{1,{ }^{*}}$ \\ ${ }^{1}$ Don State Technical University, Gagarin sq, 1, Rostov- on-Don, 344003, Russia \\ ${ }^{2}$ Moscow State University of Psychology and Education, Sretenka st,29, Moscow, 127051 Russia \\ ${ }^{3}$ Southern Federal University, 105/42 Bolshaya Sadovaya Str., Rostov-on-Don, 344006, Russia
}

\begin{abstract}
The article discusses the features of perceptual attitudes in the process of cognition of employees of the organization. Evaluation is understood as a manifestation of the evaluative component of thinking about another, and the perceptual attitude as a person's predisposition to perceive, act and evaluate the subject of interpersonal interaction in a certain way. The features of understanding evaluations in modern psychology are revealed, and the role of the evaluation component in thinking about another person is shown. The article presents socio-demographic professional factors that influence the formation of both employee and employee evaluations by the Manager. The main results of the study are described, indicating that the nature of self-esteem (overestimated or underestimated self-esteem) and the perceptual attitudes of the Manager determine the General trend of employee reflection. The identified trends and features of interpersonal cognition, the preservation of which is provided by setting mechanisms, reflect the attitude to individual qualities that managers have formed in the process of joint activities in terms of their significance for the implementation of the goals of the activity. However, changes in the goals of activities also lead to changes in the direction and nature of assessments from the outside.
\end{abstract}

\section{Introduction}

Experimental research that focuses on various aspects of organizational behavior opens up opportunities for a deeper and more complete understanding of the mechanisms underlying the development of thinking about another person.

In the conditions of activity in the organization, it is possible to distinguish cognitive activities aimed at: first, to reveal the patterns of objects of professional activity, and secondly, to reveal the psychological characteristics of the personality of employees of the organization. Thus, the processes of cognition directed at others are included in the professional activity of each person, especially for managers of organizations whose activities and functions are directly related to the coordination of communication and interaction of people, managing them to achieve the goals of the organization.

\footnotetext{
*Corresponding author: vlad_ermak197220@mail.ru
} 
Research on interpersonal cognition, which has become widespread in recent years, makes it possible to trace how thinking directed at another person develops (Vyshkvyrkina M.A.[1], Grinko A.A.[2], Panferov V.A., etc.).

The greatest difficulties in solving this issue arise when trying to differentiate the real contribution of social, socio-psychological and psychological factors to the dynamics of the formation and development of evaluation stereotypes that determine the strategic and tactical aspects of interpersonal cognition. In the research of M.A. Vyshkvyrkina and A.A. Grinko, it was shown that the stability of interpersonal cognition is determined by individual psychological characteristics of stabilizing factors-personal attitudes. At the same time, the dynamics of labor content ensures a change in people's attitude to work, reveals new qualities and capabilities of a person, and changes people's relationships with each other. Changes in the psychology of people, the development of personality in the course of work is the basis of the contradiction between the stabilized attitudes to a person and his new personal content.

In modern science, the problem of interpersonal cognition in organizations of various types is quite actively studied, however, most often the authors study the perception of the Manager by subordinates, taking into account some additional factors, such as the gender of the Manager and subordinates (Becker J., Ayman R., Korabik K. [3], Van Quaquebeke N., Knippenberg D., Brodbeck F.[4]), leadership style and competence of the Manager (Molero F., Moriano J. Shaver P. [5], Larina N.V.[6]), and others. R. B., Subbotin Yu. p. conducting extensive research, we developed and tested a system model of the Manager's perception by subordinates. Based on the results obtained, the authors proved the dependence of perceptual attitudes and processes on the socio-demographic characteristics of the organization's employees: gender, age, joint work experience, education and skill level. At the same time, the authors point out that the first three factors determine perceptual attitudes to a greater extent [7]. The increased interest in this issue can be explained because the result of thinking directed at another person, the features of social perception and the correctness of the image of the Manager as a whole, based on them, can both negatively and positively affect the formation, development and functioning of the organization, as well as affect the formation of professional identity and self-consciousness [8].

Agreeing with the point of view of S.I. Spivak [9], that managers are always perceived individually, while subordinates are perceived stereotypically, we consider it necessary to investigate the peculiarities of perception and cognition of their co-workers by the Manager. Such research will help improve the accuracy of employee evaluation and, as a result, ensure career growth for the best specialists, prepare personal growth and development programs for employees, and so on.

However, one of the most significant points in the first phase of the study of interpersonal cognition in an organization is the need to empirically identify General trends in the formation of perceptual attitudes of managers that distort the objective characteristic of the employee's personality.

\section{Materials and Methods}

To achieve the main objectives of the study, it was decided to use a methodology that allows you to record and visually display the features of perceptual attitudes of managers when they perceive and evaluate the people around them-employees of the organization.

The object of the study was managers who hold the position of deputies, assistants to the shop Manager, the shop Manager of one of the industrial enterprises. In the structure of cognition processes directed at another person, we were interested in the perceptual attitudes of representatives of this group of people.

The essence of the method is as follows: all participants in the experiment were offered a list of evaluated persons and evaluation sheets with a list of 25 qualities, summarized in 
groups: attitude to work, business qualities, relationships with others, authority. Each master evaluated the direct Manager, as well as the deputies and the head of the shop, with whom he had to interact directly and communicate in connection with the specifics of production activities. With the help of evaluation sheets, the subjects concretized the generalized image of these people, implementing it in the form of assessments of the proposed qualities. Each quality had to be evaluated in the range from 2 to 5 points.

Along with cut of marks obtained by the line of vertical relationship in the production was cut estimates in the structure of horizontal relationships: aides, assistants, foreman was required to assess the severity of each and 25 qualities, thereby specifying an existing they have a General idea about each. It was this cross-section of ratings that interested us most of all.

Each Manager was evaluated by an average of 12-15 people. In psychological literature, this number of respondents is estimated as the most optimal for adequate reproduction of the personality image and for obtaining results with a low level of error [10]. When processing the Bank of received ratings, the average and range of confidence intervals for each quality were calculated for all managers. A generalized portrait of the Manager was displayed on the evaluation sheets, and the space limited by the upper and lower limits of the confidence intervals for each quality represented a group assessment of the individual. The choice of respondents included in the vertical and horizontal structures of relationships allowed avoiding the influence of interpersonal cognition features characteristic of each level of the management hierarchy, which provided guarantees of obtaining the most appropriate image of each Manager.

Production activities in this workshop were organized in such a way that the tasks of one of the services involved the participation of all other services. The existing structure of joint production activities provided constant business communication between managers and performers on the joint solution of production tasks, creating conditions for the emergence and stabilization of the attitudes of each Manager.

The method was intended to identify how the views of managers differ from the generalized portrait of a particular person. The dynamics of managers ' evaluations was traced on a sample of 9-10 people: each Manager had to evaluate an average of 10 people-employees of the organization, who received a generalized assessment that reflects the generalized opinion that has developed in this production / team about the individual in relation to joint production activities. In this case, the group assessment served as a standard for an adequate or accurate assessment of the individual. The psychological literature recognizes the use of group survey data and test results as criteria, comparison with which allows us to judge the degree of accuracy or adequacy of cognition [11].

The ratings received from managers were compared with the average ratings for all qualities for each person being studied. If the assessment fell within the space limited by the limits of confidence intervals for each quality, it was considered adequate, if it did not fall, it was considered inadequate. The ratio of the number of inadequate or adequate ratings to the total number of received ratings was accepted by us as the coefficient of inadequate or adequate rating.

To solve the second task of the study, we used a sociometric method that allowed us to determine the business and emotional status of managers, and the method of A.L. Zhuravlev to identify the severity of individual components of the leadership style. The study also used the bass B. orientation questionnaire, which allowed to diagnose the degree of development in managers of various types of orientation, as well as the B.I. Dodonov questionnaire, which was used to determine the type of General emotional orientation. 


\section{Results}

For each Manager, the coefficients of adequate and inadequate cognition were determined and the results were presented in table 1.

Table 1. Ratio for measuring the accuracy of managers ' ratings.

\begin{tabular}{|c|c|c|c|c|c|c|c|c|c|c|c|c|}
\hline \multirow{2}{*}{ Resp } & \multicolumn{3}{|c|}{$\begin{array}{c}\text { Relations with } \\
\text { others }\end{array}$} & \multicolumn{3}{c|}{ Business skills } & \multicolumn{3}{c|}{ Attitude to work } & \multicolumn{3}{c|}{ Authority } \\
\cline { 2 - 16 } & Rev & AdA & Und & Rev & AdA & Und & Rev & AdA & Und & Rev & AdA & Und \\
\hline I & 0.09 & 0.79 & 0.12 & 0.20 & 0.66 & 0.14 & 0.24 & 0.65 & 0.21 & 0.12 & 0.44 & 0.44 \\
\hline II & 0.12 & 0.63 & 0.25 & 0.02 & 0.85 & 0.14 & 0.08 & 0.77 & 0.15 & 0 & 0.74 & 0.26 \\
\hline III & 0.37 & 0.35 & 0.28 & 0.61 & 0.33 & 0.06 & 0.50 & 0.26 & 0.24 & 0.33 & 0.67 & 0 \\
\hline IV & 0.64 & 0.36 & 0 & 0.43 & 0.57 & 0 & 0.46 & 0.54 & 0 & 0.70 & 0.30 & 0 \\
\hline V & 0.01 & 0.51 & 0.48 & 0.01 & 0.48 & 0.51 & 0 & 0.37 & 0.63 & 0 & 0.46 & 0.54 \\
\hline VI & 0.58 & 0.26 & 0.16 & 0.31 & 0.40 & 0.29 & 0.43 & 0.33 & 0.24 & 0.15 & 0.63 & 0.22 \\
\hline VII & 0.05 & 0.53 & 0.42 & 0 & 0.44 & 0.56 & 0 & 0.50 & 0.50 & 0.03 & 0.51 & 0.46 \\
\hline VIII & 0.16 & 0.65 & 0.19 & 0.04 & 0.67 & 0.29 & 0.07 & 0.55 & 0.38 & 0.05 & 0.81 & 0.14 \\
\hline IX & 0.05 & 0.67 & 0.28 & 0.06 & 0.51 & 0.43 & 0.02 & 0.74 & 0.24 & 0.07 & 0.85 & 0.08 \\
\hline X & 0.03 & 0.77 & 0.20 & 0.05 & 0.81 & 0.14 & 0.06 & 0.81 & 0.13 & 0 & 0.88 & 0.12 \\
\hline
\end{tabular}

Remark: Rev - revaluation, AdA - adequate assessment, Und - undervaluation.

Analysis of the data presented in the table allowed us to classify adequate assessments into three levels of low, medium and high adequacy. It was decided to consider coefficients ranging from 0.10 to 0.40 as coefficients with a low level of adequacy. $30 \%$ of managers ' ratings were within these limits. "Co-coefficients lying in the range of 0.40 to 0.60 " - assume a medium level of adequately-STI (20\% of managers) and lies in the range between 0.60 and higher coefficients high level of adequacy. Only half of managers $(50 \%)$ are characterized by adequate knowledge of people, the ability to more or less accurately "read " the behavior of others, revealing behind it the real motives that determine the direction of human behavior.

In order to evaluate which groups of qualities are evaluated more accurately, we will find the average coefficients of adequate evaluation for all groups of qualities. As a result of this operation, the following data were obtained: for the first group of qualities, $\mathrm{DAC}=0.55$, for the second group of qualities, $\mathrm{DAC}=0.57$; for the third group, $\mathrm{DAC}=0.55$, and for the fourth group, DAC $=0.63$.

Qualities that Express a person's authority are evaluated most accurately, and business qualities are ranked second in terms of accuracy. As a rule, an undifferentiated assessment of the General position of the individual is most accurately given, reflecting the importance that this person has in his production team. Much more difficult is the process of cognition, when it is necessary to reveal the external characteristics of behavior that determine its motives, to find out the meaning of each action for a person. A more detailed and accurate "reading" of another person's personality is hindered by the stabilizing components of interpersonal cognition, formed attitudes that fix actual cognitive activity in a certain direction, without giving a person the opportunity to change the existing ideas about another person.

At the same time, the process of learning business qualities differs in a certain dynamic: in the course of joint activities, contradictions often arise between the existing ideas about this quality of personality and the manifestation of this quality in specific situations of activity. Joint activity concretizes ideas about people and leads to changes in attitudes. Knowledge of the real capabilities of people, an adequate perception of business qualities to a certain extent affects the success of solving production tasks, so the disclosure of the capabilities of each person in the structure of business relations is, as it were, part of the production activities of managers. This circumstance can explain the fact of a more accurate knowledge of the business qualities of participants in joint activities. 
Processes of inadequate cognition are expressed by two tendencies, represented by underestimated and overestimated assessments of personal qualities. Let's look at the special manifestations of each trend.

$20 \%$ of managers consistently underestimate all groups of qualities (we were interested in coefficients with a high level of underestimation). To find out which groups of qualities are underestimated by managers most of all, average underestimation coefficients were found for each group of qualities: for the first group of qualities $\mathrm{K}=0.22$, for the second group of qualities $\mathrm{K}=0.26$, for the third group $\mathrm{K}=0.27$, for the fourth group $\mathrm{K}=0.23$. The presented data show that the lowest rating $(\mathrm{K}=0.22)$ is given to the qualities that Express the attitude to work.

When analyzing overestimates, the following data spread was obtained: the main group of revaluations was located in the range from 0 to $0.20 .30 \%$ of managers had a pronounced tendency to overestimate, and their ratings ranged from 0.30 to 0.80 . The most overestimated ratings are presented in the group of qualities that Express relationships with others $(\mathrm{K}=0.21)$. A significant number of reassessments are observed in the group of qualities that Express attitude to work $(\mathrm{K}=0.19)$. The average coefficients for the other groups of qualities are arranged as follows: for business qualities $\mathrm{K}=0.17$, for qualities that Express authority, $\mathrm{K}=0.16$.

If we compare the average coefficients that characterize the two trends in interpersonal cognition, we can see that the qualities that Express the attitude to work are most inadequately reflected in both cases $(\mathrm{CP}=0.19$ and $\mathrm{CI}=0.27)$. It turns out that one of the most important relationships in the personality structure is "read" or perceived inaccurately by managers. Thus, managers do not see the factors that determine them, first of all, the attitude of a person to work, behind the externally manifested characteristics of behavior, thereby demonstrating their inability to correctly assess a person's personality, focusing only on external manifestations of activity (expressed in business qualities-evaluated most adequately: $\mathrm{Ka}=0.57$ ) and not noticing what is behind them.

Assessments of a group of qualities that Express attitude to others are characterized as follows: first, these are the most highly overestimated qualities and, second, the lowest underestimated qualities. We can say that this group of qualities for managers does not act as a subject of knowledge. Managers ' assessments Express rather the General idea of relationships with people that was originally formed and now affects the processes of knowing another person. Overestimated assessments of this group of qualities also indicate that people's relationships to each other do not attract managers, whose interests and cognitive capabilities are focused around what is directly and directly related to production activities. This ignores an important aspect of the Manager's management activity, which requires knowledge of the socio-psychological capabilities of teams, which reflect the features of people's relationships.

The total number of ratings obtained as a result of the study can be arranged as follows: in terms of representation, adequate surveys dominate (56\% of the total number of ratings), followed by low ratings (25\%) and high ratings (19\%). Thus, in the General direction of inadequate cognition, the underestimation of the real capabilities of others dominates, which can lead to the appearance of negative psychological and socio-psychological consequences.

Out of the total number of managers surveyed, $30 \%$ tend to overestimate others and $20 \%$ tend to underestimate them. The willingness to overestimate or underestimate the personal qualities of others was shown in managers when evaluating representatives of various structural levels of management (subordinates, colleagues, managers). This readiness was present in each Manager when evaluating the coolness of individuals from 9-10 people, while maintaining its focus in each individual case, which allows us to recognize the identified trends as stable and inherent in managers as one of the components of interpersonal cognition. Since the preservation of the direction in the implementation of any type of activity is 
provided by the attitudes of the appropriate level, the highlighted trends are a manifestation of the attitudes of managers that have been formed and fixed in interpersonal cognition. These General trends are expressed in the nature of the Manager's willingness to evaluate individual qualities of people around them. For example, managers (IV) and (VI) from $80 \%$ to $90 \%$ of ratings are overestimated (both have a tendency to overestimate) for the following qualities: "honesty", "modesty", "trust in people", "self-control".

Managers who have the opposite tendency also maintain stability in the nature of evaluations. The Manager (III), among all other qualities, almost everyone underestimates such a quality as "decency in behavior". The Manager (V) in $80 \%$ of cases underestimates such qualities as "honesty", "decency in behavior", "ability to learn new things", "attitude to professional development".

It was revealed that individual managers have some features of interpersonal cognition that seem to "fall out" of the General trend inherent in this person. For example, a Manager (III) with a tendency to overestimate qualities in $90 \%$ of cases, understates such a quality as "modesty". With a General tendency to adequately assess others, the Manager (VIII) in 70\% of cases underestimates the quality of "sense of responsibility", the Manager (IX) underestimates the quality of "perseverance, energy". These features are evident in managers when evaluating a fairly representative sample of people and retain their direction in almost all cases. In this connection, we can assume that these features of interpersonal knowledge of managers are determined by the functioning of their attitudes.

The identified trends and features of interpersonal cognition, the preservation of which is provided by setting mechanisms, reflect the attitude to individual qualities that managers have formed in the process of joint activities in terms of their significance for the implementation of the goals of the activity. However, the goals of activity change, which is determined by the development and dynamics of production and social processes. The new goals are accepted by the actors. And in the process of their implementation, the significance of individual qualities of others changes. Such processes lead to changes in the direction and nature of assessments on the part of managers (as well as other subjects of knowledge).

To identify the role of psychological and socio-psychological factors that influence the formation of interpersonal cognition features, studies were conducted that allowed us to obtain data on individual characteristics of the managers ' personality. The methodological apparatus was used to establish the sociometric status of managers, management style, and orientation, the overall emotional orientation.

We analyzed the features of the studied group of managers obtained as a result of using the methods. The orientation of the individual is one of the most important characteristics that allows you to determine what can act as the motives of managers. $80 \%$ of managers have a business focus, while the rest have a personal focus, but they have a business focus in the second place in terms of representation. All this indicates the high importance of business orientation in the structure of psychological qualities of the individual. For the position of a manager, the development of interpersonal orientation is professionally significant, since the manager first of all has to work with people. However, only $40 \%$ of managers have a developed interpersonal orientation (ranked second in terms of representation). This data is consistent with the results obtained in determining the overall emotional orientation: $80 \%$ of managers experience mainly praxic experiences. As for the emotions associated with communication, a significant proportion of communicative experiences in the structure of the overall emotional orientation is observed in $40 \%$ of managers.

According to the results of a sociometric study, $60 \%$ of managers have a high business status, and $40 \%$ have a low one. According to the emotional criterion, only $20 \%$ of managers have a high status. Presumably, the high business status can be explained by the dominance of the business orientation: the presence of a business orientation makes it easier to separate the Manager from the group, increases his status. This may be facilitated by the fact that the 
structure of the General emotional orientation is dominated, along with praxic, and gnostic experiences ( $70 \%$ of managers). All this allows us to say that, firstly, the cognitive component occupies a significant place in the structure of management activities, and secondly, the combination of business orientation and Gnostic experiences indicates a creative approach to the implementation of activities, which ensures an increase in the status of the Manager.

In the process of using the technique of A.L. Zhuravlev, data were obtained that reveal the structure of the individual management style. Analysis of the data presented in table 2 suggests that the collegial component of the style dominates $70 \%$ of managers, $20 \%$ have a Directive component, and $10 \%$ have a consumer component. The conducted research has shown that the formation of the character of attitudes underlying interpersonal cognition is determined by such personal factors as orientation, self-esteem, which are superimposed on the system of relationships and determine the General style of the Manager's activity.

For managers with a tendency to inadequate knowledge of both overestimating and underestimating the assessments of others, the following combination of different types of orientation is characteristic: business orientation is in the first place, then personal orientation, and only in the third place - interpersonal orientation. In this case, the role of activity and official status in the management hierarchy can be traced, which require a person to primarily deal with tasks related to production activities.

Table 2. Structural components of management styles.

\begin{tabular}{|c|c|c|c|}
\hline The Head & Collegiate & A Decision-Making & Permissive \\
\hline I & 3.4 & 2.4 & 1.0 \\
\hline II & 3.1 & 1.3 & 0.8 \\
\hline III & 3.5 & 0.8 & 0.8 \\
\hline IV & 3.1 & 1.5 & 0.9 \\
\hline V & 1.2 & 1.2 & 1.9 \\
\hline VI & 5.5 & 13.2 & 4.6 \\
\hline VII & 11.4 & 10.4 & 2.1 \\
\hline VIII & 4.4 & 1.5 & 1.9 \\
\hline IX & 2.0 & 1.5 & 1.7 \\
\hline X & 2.0 & 1.8 & 1.0 \\
\hline
\end{tabular}

For managers with an adequate trend of interpersonal cognition, the distribution of types of orientation is characterized by the fact that $80 \%$ of them have an interpersonal orientation in second place, and personal orientation in third place. It can be assumed that the combination of the dominant business and interpersonal orientation is one of the factors that ensure adequate cognition. Business orientation contributes to the fact that a person perceives the surrounding objects as tasks that need to be solved. Interpersonal orientation allows you to expand the range of subjects to include a person, thereby orienting the subject of knowledge to establish the relationship between behavior, human activity and the personal characteristics that stand behind them, which ensures the greatest adequacy of the known.

In the literature [12], there is evidence of a more adequate assessment of others carried out by a "business" leader compared to an "emotional" one. In our study, $60 \%$ of managers had a high business status and low emotional status. Among the managers who adequately assess others, $60 \%$ had a high business status, $40 \%$ - a low one. The results obtained are consistent with the data available in the literature on the influence of a person's position in a group on the processes of knowing another.

There is no clear conclusion as to whether the status affects the inadequacy of reflection. Managers who perform inadequate reflection (both overestimation and understatement of ratings) are characterized by both high $(50 \%)$ and low (50\%) business status. One Manager 
has a high emotional status. In this case, we are not able to talk about the influence of the individual's status in the group on the inadequacy of interpersonal cognition.

The analysis of the received self-assessments and their correlation with the coefficients that Express the measure of accuracy of managers ' assessments allows us to conclude that the more accurately a person reflects himself, the more adequately he evaluates others. $60 \%$ of managers who perform adequate cognition have self-assessment adequacy coefficients ranging from 0.56 to 1 .

\section{Discussion}

Thus, we can say that the nature of self-esteem affects interpersonal cognition: adequate selfesteem ensures the adequacy of other people's cognition. The study found evidence to support the assumption that self-esteem (over-or under-self-esteem) determines the General tendency to reflect others. At the same time, this conclusion exists only in relation to a limited number of participants, which does not allow us to consider it unambiguous and proven. However, similar results were obtained in studies on adolescents, students and managers [13-15], as well as in the study of J. Becker, R. Ayman, K. Korabik, which proved significant discrepancies between the self-perception of managers of different gender and type of organizations and the perception of its employees. The biggest differences the authors found in the estimates of women managers of industrial enterprises, and minimal differences in the group of women heads of education and male managers in the industrial sector, which in our opinion, indicates the effect of perceptual attitudes and stereotypes in evaluations of leaders, and in assessments of their employees.

\section{Conclusions}

Based on the study the following conclusions can be drawn:

1. Interpersonal cognition as one of the types of activity is based on the attitudes formed in the course of joint activities.

2. Attitudes in interpersonal cognition serve as stabilizing factors, determining the nature of the direction of people's cognition.

3. In inadequate interpersonal cognition, which distorts the accurate assessment of a person, two trends can be distinguished: overestimation and underestimation of the assessments of others.

4. The adequacy of assessment can be the result of the mental activity of managers, which arises as a result of independent, involuntary formulation and solution of the problem associated with the knowledge of the subordinate.

These tasks are formed in the course of detecting a discrepancy between the actual perceptual attitude and the real behavior of a person in a production situation. The subject of thinking in this case is the employee's personality, and the result of knowledge is the dynamics of perceptual attitudes, their scrapping and correction. That is why, it seems to us, people with an adequate assessment of the other find a certain combination of business orientation with interpersonal, while for those who do not adequately assess, a combination of business orientation with self-orientation (personal orientation) is characteristic. Thinking, therefore, acts as a necessary link in the mechanism of formation of adequate perceptual attitudes. On the other hand, the absence of thinking aimed at knowing the other guarantees the inadequacy of evaluation, knowledge that is also provided by rigid, rigid attitudes, which is why the tendency to overestimate or underestimate the assessment of subordinates extends both to the entire set of evaluated qualities and to all evaluated subordinates. 
Thus, the conducted research allows us to directly set the task of analyzing the sensitivity to "human " problems (cognition of the other) in managers of different ranks as a basal component that determines the initiation of thinking, during which more and more adequate precise attitudes are formed, ensuring the adequacy of the assessment of the personality of employees.

\section{References}

1. A.K. Belousova, M.A. Vyshkvyrkina, et al, 11th International technology, education and development conference (IATED, Barcelona, 2017) DOI:10.21125/inted.2017.0083

2. A.K. Belousova, A.A. Grinko, International journal of psychology S1(51), 189-190 (2016) DOI: 10.1002/ijop.12299

3. J. Becker, R. Ayman, K. Korabik, Group \& Organization Management 27(2), 226-244 (2002) DOI:10.1177/10501102027002004

4. N. Van Quaquebeke, D. Knippenberg, F. Brodbeck, The Leadership Quarterly 22, 367382 (2011) DOI:10.1016/j.leaqua.2011.02.011

5. F. Molero, J. Moriano, P. Shaver, The Spanish journal of psychology 16(E62), 1-10 (2013) DOI:10.1017 / sjp.2013.67

6. N.V. Larina, Vestnik IRGTU 3(86), 180-184 (2014)

7. R.B. Gitelmakher, Yu.P. Subbotin, Sociological research 7, 83-93 (1992)

8. L. Ross, R.E. Nisbett, M. Gladwell, The person and the situation: Perspectives of social psychology (Pinter \& Martin, London, 2011)

9. S.I. Spivak, Methods of research of psychological structures and their dynamics 3, 7185 (2005)

10. L. Figgou, V. Pavlopoulos, Social Psychology: Research Methods. International Encyclopedia of the Social \& Behavioral Sciences (Elsevier, Florida, 2015) DOI:10.1016/B978-0-08-097086-8.24028-2

11. T.E. Malloy, Social Relations Modeling of Behavior in Dyads and Groups (Academic Press, NY, 2018) DOI:10.1016/C2016-0-02324-0

12. A.A. Bodalev, Perception of a person by a person (Publishing house "EncyclopedistMaximum", Moscow, 2015)

13. G. Kozhukhar, A. Belousova, 9th International conference on education and new learning technologies (EDULEARN17) (IATED, Barcelona, 2017) DOI:10.21125 / edulearn.2017.2311

14. A. Belousova, Yu. Mochalova, Behavioral Sciences 10(3), 68 (2020) DOI:10.3390/bs10030068

15. M. Vyshkvyrkina, International Journal of Cognitive Research in Science, Engineering and Education 1(1), 36-41 (2013) 